\title{
CORRELATION OF TEXTURE WITH MAGNETIC PROPERTIES OF THIN FILM STORAGE MEDIA
}

\author{
E. HÄDICKE, A. WERNER and H. HIBST \\ BASF Aktiengesellschaft, Ammoniaklaboratorium, D-6700 Ludwigshafen, \\ Germany
}

Thin coherent metal films of $\mathrm{Co}-\mathrm{Cr}$ alloys on $\mathrm{Si}$ or glass substrates were used for high density magnetic storage media. They were made by sputtering or evaporation. Variation of the deposition parameters will change the micro structure especially the texture of the thin magnetic layers. We could relate the crystallographic data (rocking curves and pole figures) with the magnetic data (hysteresis loops). Correlations between deposition parameters and crystallographic and magnetic investigations will be discussed in detail.

KEY WORDS Thin films, Co-Cr, sputtering, texture, sublayers, substrate temperature.

\section{INTRODUCTION}

The requirement for large amounts of data and the trend towards ever smaller equipment for storing them requires storage media with ever higher storage densities. In the case of digital magnetic recording, this calls for smaller storage regions for the individual bits.

In the magnetic recording media normally used at present, a film of organic lacquer in which magnetic pigments (usually $\mathrm{Fe}$ or $\mathrm{Cr}$ oxides) are dispersed, is applied to a substrate. In these media the storage of information takes place in the so-called longitudinal mode. In this case the required increase in storage density calls for a considerable reduction in the film thickness of the magnetic recording film. This is achieved by going over from the particulate media to coherent thin-film media. These metallic films are produced by chemical or electrochemical deposition (plating), vapor deposition or sputtering. Mostly Co-TM alloys $(\mathrm{TM}=\mathrm{Ni}, \mathrm{Cr}-\mathrm{ia}$.) are used which attain the necessary high magnetic flux and coercivity for stable storage. The metallic thin-film rigid disks being launched on the market attain storage densities which are four times higher than that of conventional ones.

Still higher storage densities can be achieved with vertical magnetic recording which is being developed throughout the world. Here, the objective is a ten-fold increase in the linear recording density, e.g. in the case of $\mathrm{Co}-\mathrm{Cr}$ alloys, compared with the present conventional recording media.

The basic parameters for magnetic storage media, such as saturation magnetization, remanent magnetic flux or coercivity, are obtained from the magnetic hysteresis curve. This curve, measured with a vibrating sample magnetometer, represents the magnetic moment as a function of the field strength.

In the case of Co-TM alloys the magnetic easy direction (direction in which magnetization is reversed at storage,) coincides with the direction of the crystallographic $c$ axis. Therefore it is essential to determine the structure of the 
storage films. This is achieved primarily with X-ray texture studies which determine the orientation of the crystallites and their distribution.

Since the orientation is already fixed during production in the case of coherent metallic thin-film media, the relationships between the production parameters, the magnetic properties and the structure are of appreciable significance for the efficacious adjustment of certain desired magnetic parameters. The saturation magnetization depends primarily on the chemical composition of the storage film. All the other static magnetic parameters, such as remanence and coercivity can be altered over a wide range by altering the morphology of the film while keeping the composition the same. We should like to use the example of sputtered $0.5 \mu \mathrm{m}$ thick $\mathrm{Co}_{80} \mathrm{Cr}_{20}$ films for vertical recording to explain these relationships.

\section{PREPARATION OF SAMPLES}

The Co-Cr films were sputtered in the RF diode mode from a target having the composition $\mathrm{Co}_{80} \mathrm{Cr}_{20}$. The sputtering parameters were an $\mathrm{Ar}$ pressure of $5 \times 10^{-3} \mathrm{mbar}$, a substrate-target distance of $55 \mathrm{~mm}$ and a sputtering rate of $18 \mathrm{~nm} / \mathrm{min}$ (target diameter $150 \mathrm{~mm}$, RF power $450 \mathrm{~W}$ ). The back-pressure was better than $10^{-7}$ mbar (turbo pump and liquid nitrogen trap). All the films which are described here have a thickness of $500 \mathrm{~nm}$ and were deposited on glass substrates and monocrystalline Si wafers with (100) and (111) orientations. The substrates were cleaned by sputter etching.

\section{MAGNETIC MEASUREMENTS}

Figure 1 gives an impression how the hysteresis loops in the magnetic hard and magnetic easy direction of a sample with uniaxial magnetic anisotropy looks like,

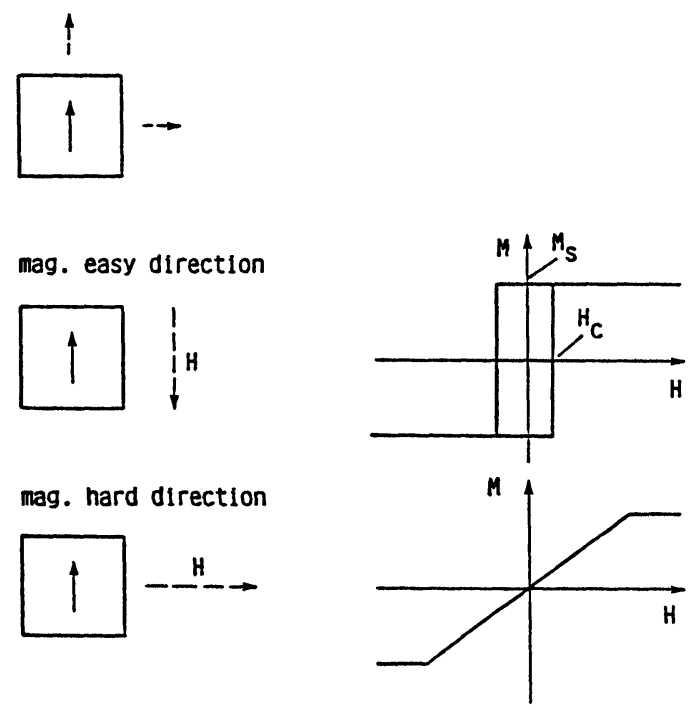

Figure 1 Hysteresis loops of magnetic uniaxial sample (ideal case). 


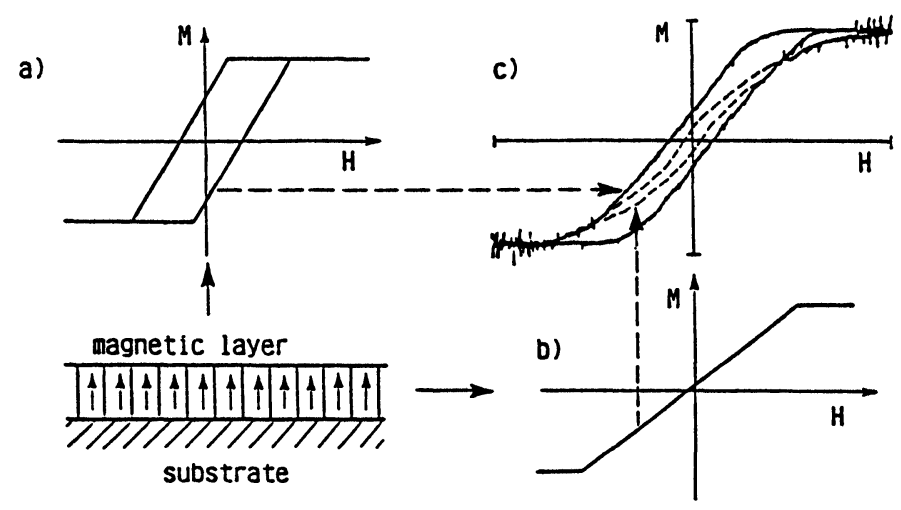

Figure 2 Hysteresis loops of a magnetic uniaxial layer with perpendicular orientation. (a) Hysteresis loop perpendicular to layer (ideal case). (b) Hysteresis loop parallel to the layer (ideal case). (c) Hysteresis loops perpendicular (-) and parallel (-- ) to the plane of a real Co-Cr-layer on glass.

in the ideal case. In the easy direction one gets a rectangular shaped curve. The area of this curve is determined by the coercivity $H_{c}$ and the saturation magnetization $M_{s}$. The hysteresis loop in the magnetic hard direction has an area of zero. So also the relative remanence in the film plane $\left(m_{r}(\right.$ para $\left.)=M_{r} / M_{s}\right)$ must be zero.

Figure 2 shows the deviation of the actual curves from the ideal curves. An ideal oriented perpendicular film of uniaxial $\mathrm{Co}-\mathrm{Cr}$ crystallites has a sheared hysteresis loop for the magnetic easy direction. This is a consequence of the film geometry which is the source of a large demagnetizing field perpendicular to the film plane. Typical measured hysteresis loops perpendicular and parallel to the Co-Cr film plane are contrasted with these ideal curves.

The hysteresis loop for the magnetic easy direction is quite similar to the ideal case. Since the back-shearing is not without problems, we use only $H_{c}$ (perpen) from that curve to characterize the sample. On the other hand the hysteresis loop for the magnetic hard direction shows a large deviation from the ideal case. There is some remanent magnetization $\left(m_{r}(\right.$ para $\left.)>0\right)$, indicating magnetic moments which are not perpendicular to the film plane. So $m_{r}$ (para) seems a good parameter for characterizing the magnetic perpendicular orientation of the $\mathrm{Co}-\mathrm{Cr}$ film. ${ }^{1,2}$

\section{X-RAY DIFFRACTION}

Co-Cr films with $\mathrm{Cr}$ contents below 30 at. $\%^{3}$ crystallize, like $\alpha-\mathrm{Co},{ }^{4}$ with a hexagonal closest packing (hcp). They form substitution mixed crystals whose crystallographic data do not differ substantially from those of the $\alpha$-Co. Figure 3 shows a diffraction diagram of $0.5 \mu \mathrm{m}$ thick $\mathrm{Co}-\mathrm{Cr}$ film on $\mathrm{Si}$. In the $2 \theta$ range of $35-55^{\circ}$ the Bragg reflexions (100), (002) and (101) of $\mathrm{Co}-\mathrm{Cr}$ are located. The planes at which diffraction takes place are shown in Figure 4.

Usually preliminary X-ray diagrams in back-reflexion are taken of thin films. The primary and secondary beam emerge on the same side of the sample and are 


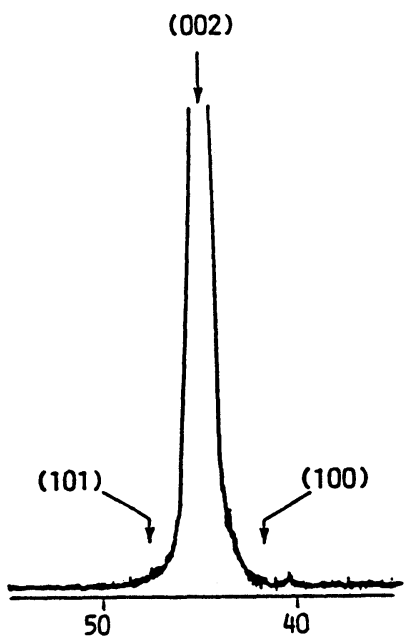

Bragg-angle $2 \theta\left({ }^{\bullet}\right)$
Figure 3 X-ray diffraction diagram of a $\mathrm{Co}-\mathrm{Cr}$ film on a $\mathrm{Si}$ substrate with a high perpendicular orientation of the $c$ axis.

in the same plane as the normal to the sample surface (Figure 5). The sample is rotated during diffraction by $\theta$ with respect to the primary beam, the detector by $2 \theta$. Since only a strong (002) reflexion occurs in the case of Figure 3, this means that, in almost all the crystallites, the $c$ axis is perpendicular oriented to the sample surface. The precise orientation of the crystallites and the distribution of their orientation is found from X-ray texture measurements using a texture diffractometer.

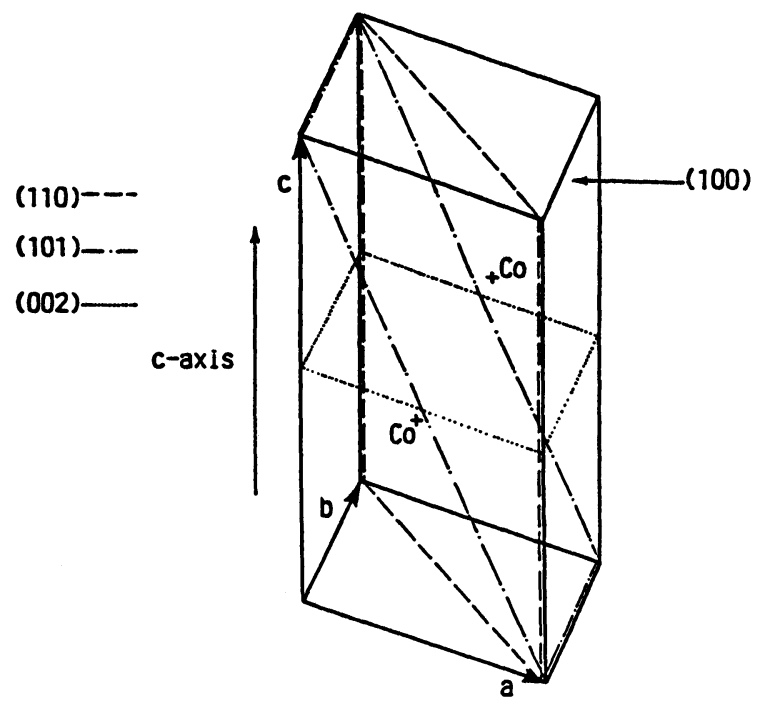

Figure 4 Unit cell of hcp Co. 


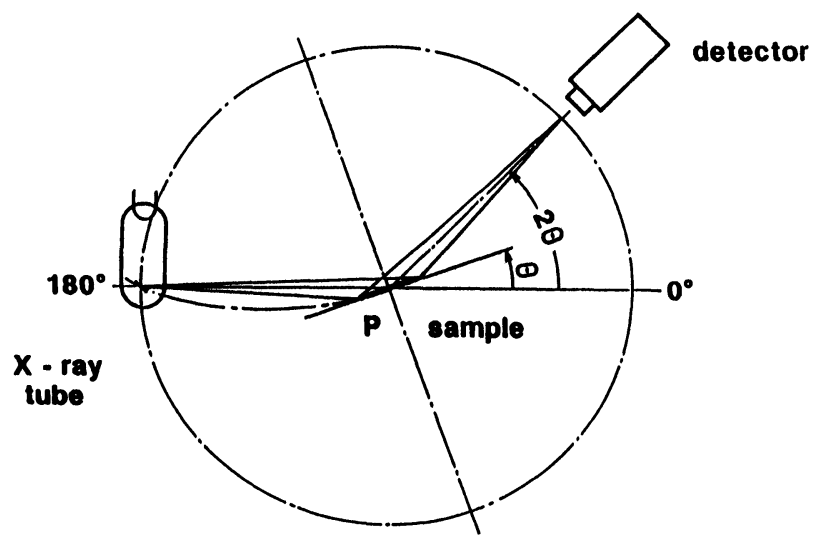

Figure 5 X-ray diffraction in back-reflexion (Bragg-Brentano focusing geometry).

In this apparatus (Figure 6), the normal to the sample can be tilted through the angle $\chi$ with respect to the diffraction plane which is formed by the primary and the secondary beam. In addition, a rotation through $\varphi$ around the normal to the sample is possible. Sample rotations during diffraction at a reflexion were represented as a pole figure in a stereographic projection (Figure 7). The reflexion intensities during the diffraction are shown as contour lines in this pole figure. Figure 8 shows the (002) pole figure of a typical Co-Cr sample. In this case, the maximum in the diffraction intensity is situated at $\chi=90^{\circ}$ at the center of the pole figure, i.e. the $c$ axis orientation is mainly perpendicular to the film surface. This distribution of the crystallite orientations is sharp, i.e. the orientations of the most of the crystallites differ only slightly from the perpendicular direction. Besides that the distribution is symmetrical, i.e. there is no preferred position in the rotation around the normal to the sample. We find this case of a sharp fiber texture in the most of our Co-Cr samples.

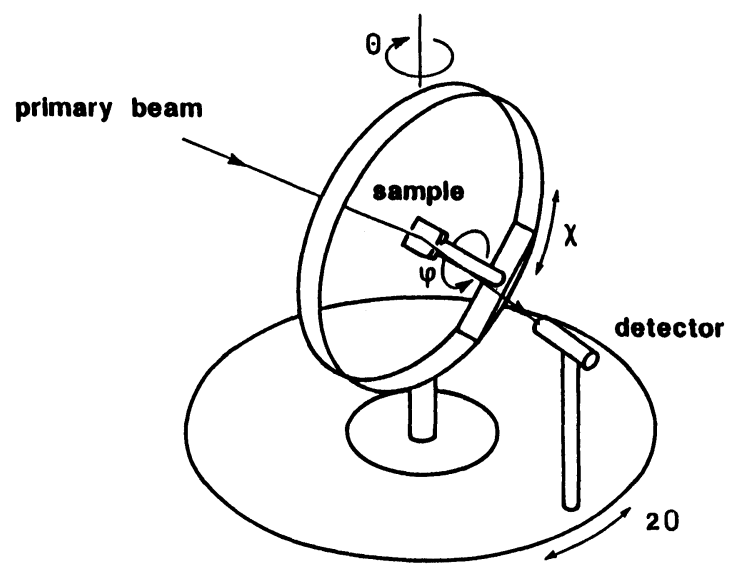

Figure 6 Geometry of texture diffractometer (back-reflexion measurement). 

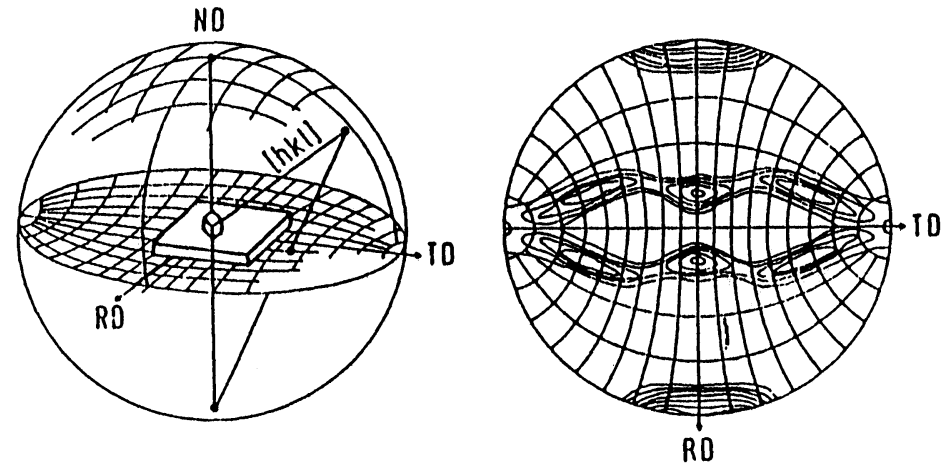

Figure 7 Definition of the (hkl) pole figure.

The sharpness of the distribution of the orientation characterizes the quality of perpendicular crystallographic orientation in $\mathrm{Co}-\mathrm{Cr}$ films. For the purpose of a precise measurement, the sample is tilted through $\theta$ (with small apertures) in the diffraction plane (with fixed $\chi$ and $\varphi$ values) and the diffraction intensity is recorded. The result obtained is a so-called rocking curve (Figure 9). In this example of a $0.5 \mu \mathrm{m}$ thick Co-Cr sample on a glass substrate, a full width at half maximum (FWHM) is obtained of $\Delta \theta=3.2^{\circ}$, indicating a very narrow distribution of the $c$ axis orientation.

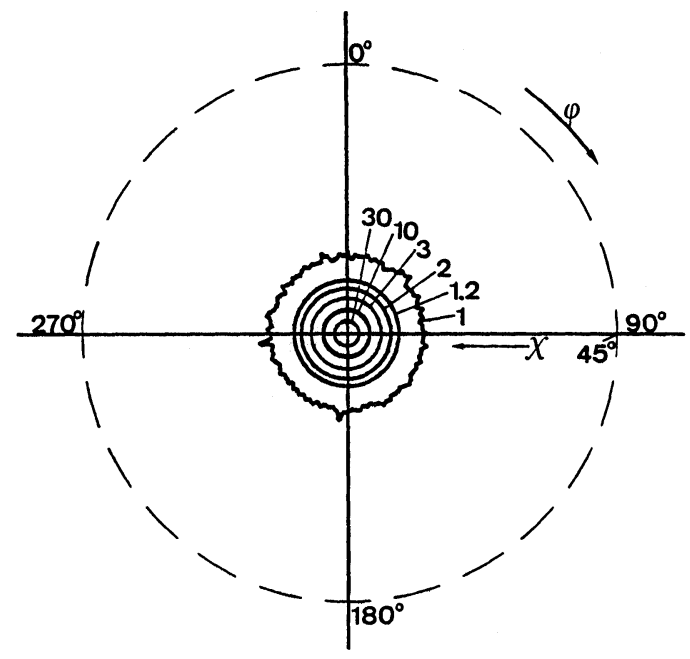

Figure 8 (002) pole figure of a $\mathrm{Co}-\mathrm{Cr}$ film on glass. 


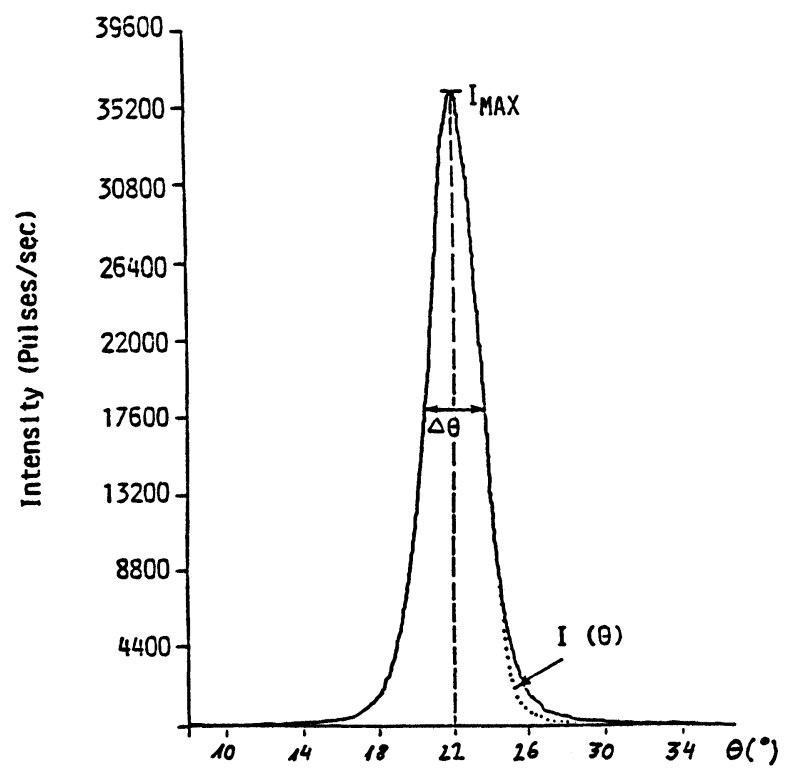

Figure 9 Rocking-curve of a Co-Cr-film on glass, $\Delta \theta=$ full width at half maximum (FWHM), $I(\theta)=$ approximation of the measured curve by a gaussian function.

\section{EFFECTS DUE TO SUBSTRATE CLEANING BY SPUTTER ETCHING AND TO SUBLAYERS}

To achieve a good perpendicular orientation of the Co-Cr films, the substrates have to be cleaned. This can be done very effectively by RF sputter etching. With a power density of $0.2 \mathrm{~W} / \mathrm{cm}^{2}$ and an Ar pressure of $5 \times 10^{-3} \mathrm{mbar}$, the etching rate of glass and $\mathrm{Si}$ with our equipment is about $1.5 \mathrm{~nm} / \mathrm{min}$. The hysteresis loops (in plane and perpendicular) of the $0.5 \mu \mathrm{m}$ thick $\mathrm{Co}-\mathrm{Cr}$ films on glass and $\mathrm{Si}$ substrates indicate a strong increase of perpendicular orientation as a consequence of cleaning (Figure 10). This can be seen particularly well from the $m_{r}$ (para) values (Figure 11). These values decrease in the case of Si and in the case of glass substrates (but by a different amount) with increasing etching time. Especially for etched Si substrates the hysteresis loop is very near the ideal case shown in Figure 1.

Optimum surface conditions for growing a perpendicular film are obtained only after an etching time of $15 \mathrm{~min}$. This means almost $20 \mathrm{~nm}$ of substrate had to be removed. ESCA measurements revealed only a $2 \mathrm{~nm}$ thick $\mathrm{SiO}_{\mathrm{x}}$ film on the uncleaned $\mathrm{Si}$ substrates, indicating a further effect in optimizing the surface through etching, besides the removal of surface contamination and oxide layers. Perhaps the change in the surface roughness during sputter etching plays a part. A delay of 15 min was allowed after sputter etching before sputtering on $\mathrm{Co}-\mathrm{Cr}$ in order to bring substrates back to room temperature. 


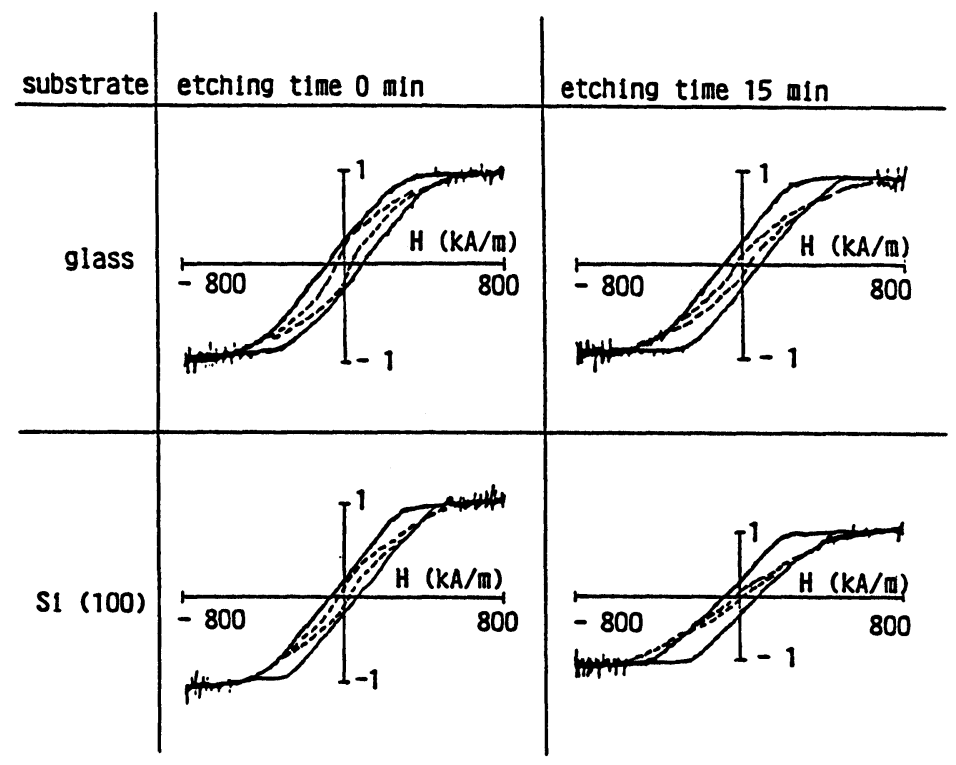

Figure 10 Hysteresis loops (perpendicular (-) and parallel (---)) of $\mathrm{Co}-\mathrm{Cr}$ films on glass and $\mathrm{Si}$ substrates, with and without etching.

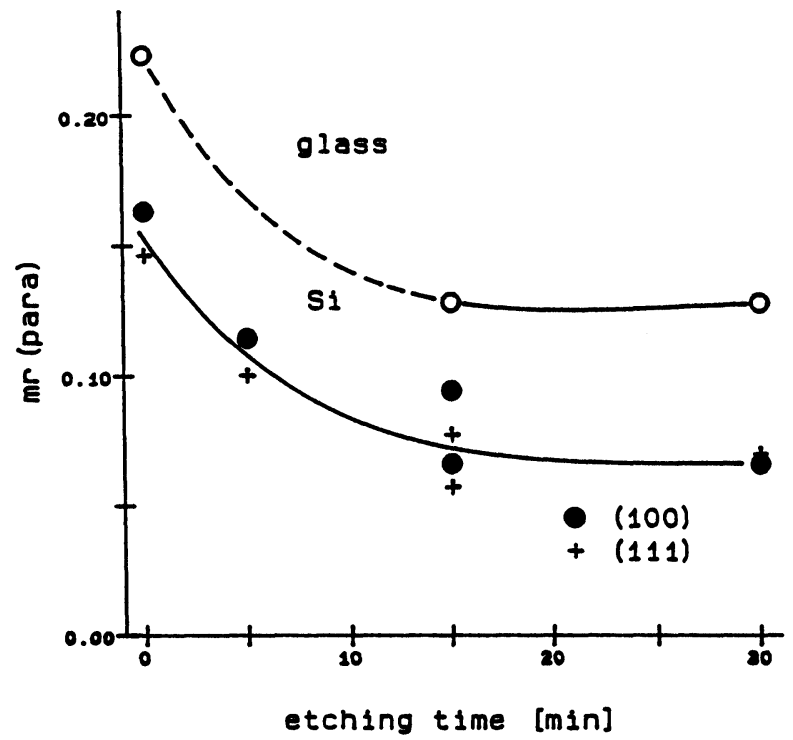

Figure 11 In plane relative magnetization $m_{r}$ (para) of $\mathrm{Co}-\mathrm{Cr}$ films on glass and $\mathrm{Si}$ as a function of etching time. 
The fact that the substrates affect the properties of the $\mathrm{Co}-\mathrm{Cr}$ films is shown by the different $m_{r}$ (para) values of the films on glass and Si (Figure 11). However, there is no hint of epitaxial growth in this case since the values of the films deposited on $\mathrm{Si}(100)$ - and $\mathrm{Si}(111)$-textured wafers are equal.

The substrates may be altered by depositing sublayers. ${ }^{5}$ Thus, it is known that Ge sublayers on plastic films increase the perpendicular orientation of the $\mathrm{Co}-\mathrm{Cr}$ films, while $\mathrm{Bi}$ sublayers reduce it. ${ }^{5}$ We investigated the effect of $\mathrm{Cr}$ and $\mathrm{Ti}$ sublayers of various thickness on glass and $\mathrm{Si}$ substrates. They were sputtered on with the same sputtering parameters as the Co-Cr films.

It can be seen from Figure 12 that Ti sublayers have only a weak influence on $m_{r}$ (para) of the Co-Cr films. For $d_{\mathrm{Ti}}>50 \mathrm{~nm}$ one observes a slight increase of $m_{r}$ (para).

In the case of $\mathrm{Cr}$ sublayers (Figure 12), $m_{r}$ (para) of the $\mathrm{Co}-\mathrm{Cr}$ films increases very markedly to 0.4 even for very thin $(5 \mathrm{~nm})$ films and then drops slightly to 0.32 at $200 \mathrm{~nm}$. The body centered cubic (bcc) structure of $\mathrm{Cr}^{4}$ is shown in Figure 13. Epitaxial considerations reveal that the atoms of the $\mathrm{Co}(110)$ plane fit particularly well on to the atoms of the $\operatorname{Cr}(200)$ plane (Figure 14). We know from our studies of the $\mathrm{Cr}$ films that the $\mathrm{Cr}$ films do not have any preferred texture. Thus, the Co-Cr films on a Cr sublayer should have a random orientation of the $c$ axis which yields high $m_{r}$ (para) values. This effect of $\mathrm{Cr}$ sublayers is made use of in preparing longitudinal magnetic media with $\mathrm{Cr}$ sublayers and Co alloys as the magnetic film. ${ }^{6}$

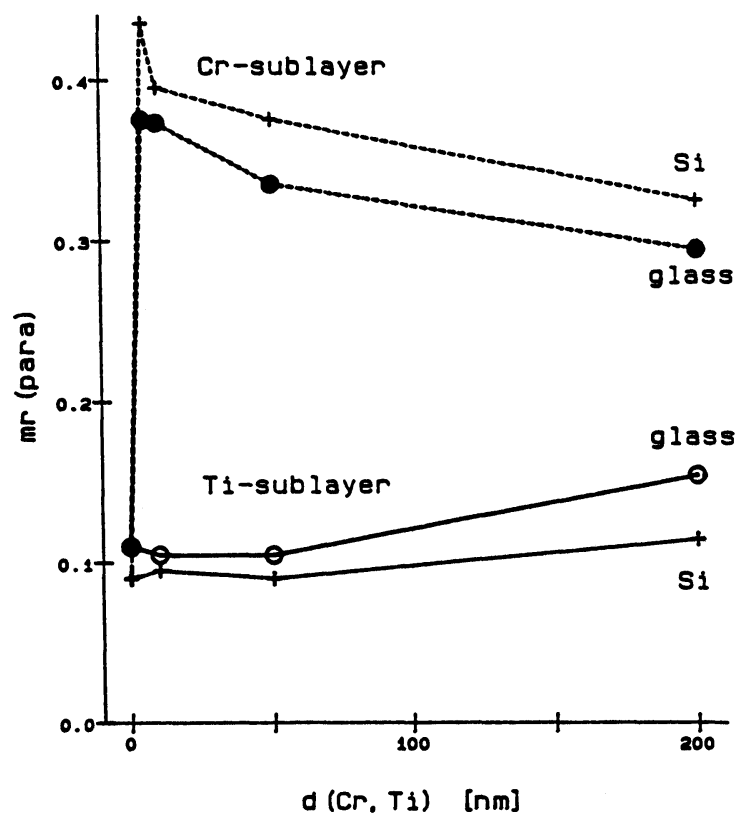

Figure $12 m_{r}$ (para) of $0.5 \mu \mathrm{m}$ thick $\mathrm{Co}-\mathrm{Cr}$ films as a function of the thickness of sublayers of $d_{\mathrm{Cr}}$ or $d_{\mathrm{Ti}}$. Used substrates are glass and $\mathrm{Si}$. 


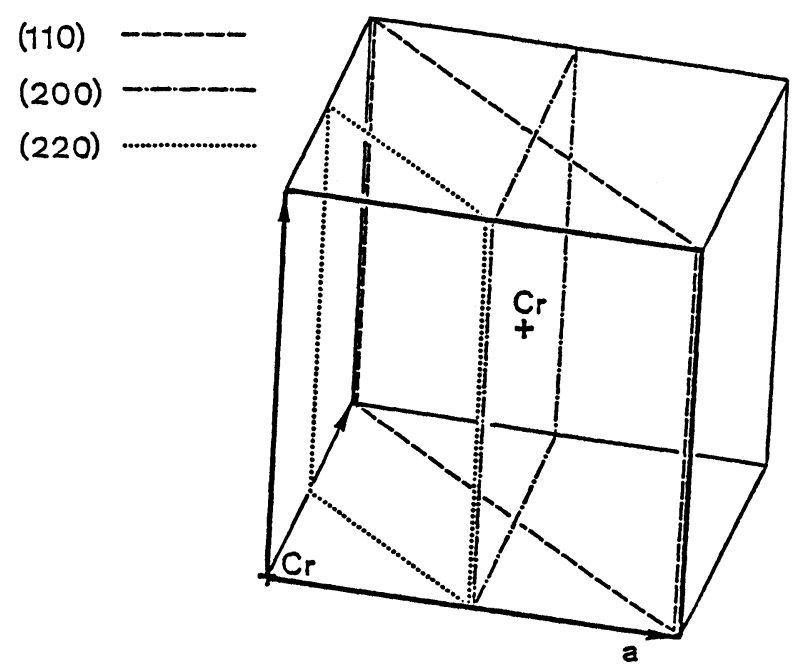

Figure 13 Unit cell of bcc $\mathrm{Cr}$.

The $H_{c}$ values of the Co- $\mathrm{Cr}$ magnetic films are also affected by the sublayers. Without a sublayer, the coercivity in the plane $H_{c}$ (para) is low $(25 \mathrm{kA} / \mathrm{m})$, while the coercivity perpendicular to the plane $H_{c}$ (perpen) is high $(90 \mathrm{kA} / \mathrm{m})$ (Figure 15). The latter is nearly independent from $d_{\mathrm{Cr}}$ whereas $H_{c}$ (para) increases markedly to $50 \mathrm{kA} / \mathrm{m}$ for $d_{\mathrm{Cr}}=50 \mathrm{~nm}$ and remains constant up to $d_{\mathrm{Cr}}=200 \mathrm{~nm}$.

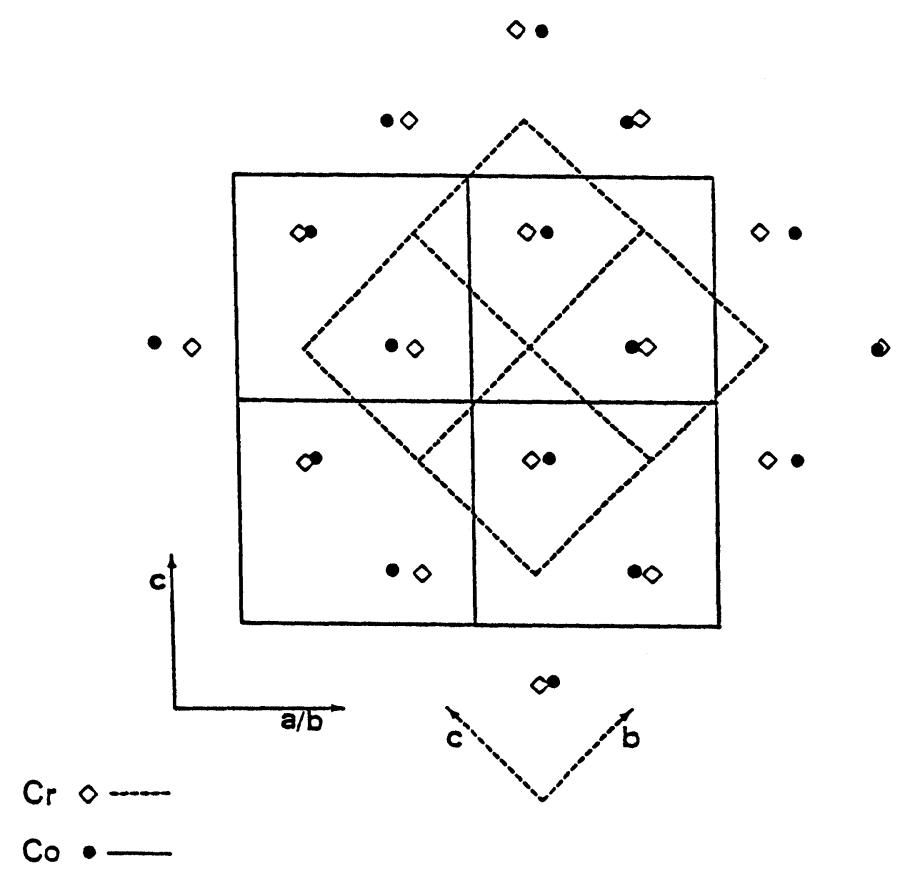

Figure 14 Surfaces of $\operatorname{Co}(110)$ and $\operatorname{Cr}(200)$. 


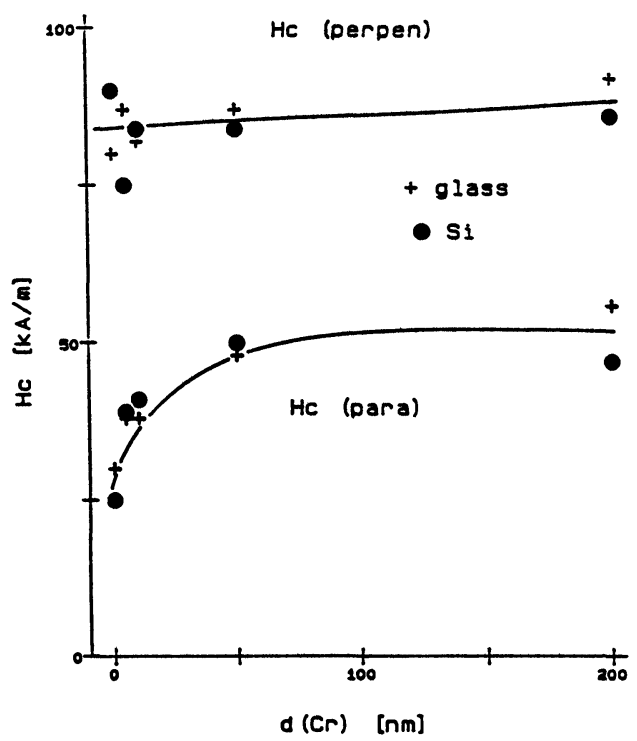

Figure 15 Coercivity $H_{c}$ of $0.5 \mu \mathrm{m}$ thick Co-Cr films as a function of the thickness $d_{\mathrm{Cr}}$ of the $\mathrm{Cr}$ sublayer.

For $\mathrm{Ti}$ sublayers the situation is quite different (Figure 16). $H_{c}$ (perpen) drops from $90 \mathrm{kA} / \mathrm{m}$ to $50 \mathrm{kA} / \mathrm{m}$ for $d_{\mathrm{Ti}}=50 \mathrm{~nm}$. With increasing thickness of the sublayer, $H_{c}$ (perpen) rises to $145 \mathrm{kA} / \mathrm{m}$ at $d_{\mathrm{Ti}}=200 \mathrm{~nm}$. An increase of $H_{c}$ (perpen) with increasing $d_{\mathrm{Ti}}$ was also published in Refs 6 and 7. The reason shall be a morphological change towards a columnar Co-Cr layer, using a $\mathrm{Ti}$ sublayer. ${ }^{7}$

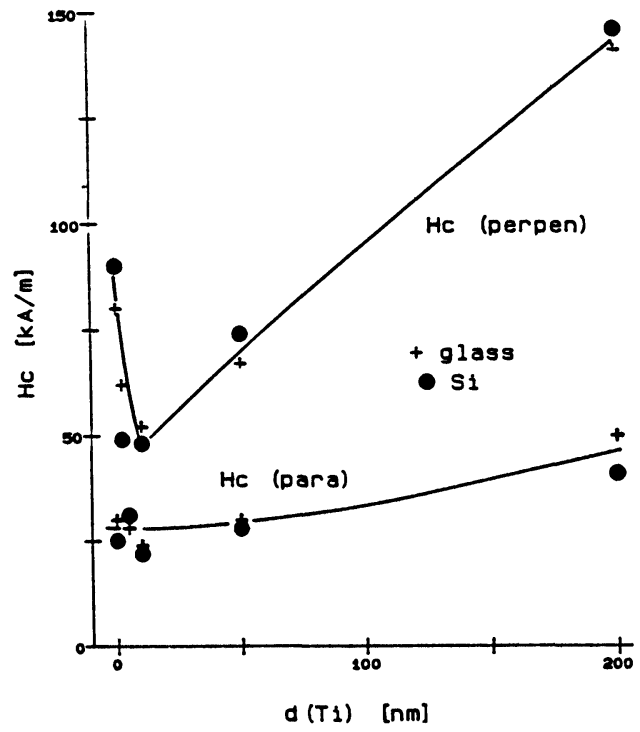

Figure 16 Coercivity $H_{c}$ of $0.5 \mu \mathrm{m}$ thick Co-Cr films as a function of the thickness $d_{\mathrm{Ti}}$ of the Ti sublayer. 


\section{EFFECT OF SUBSTRATE TEMPERATURE}

The temperature of the substrate during the sputter deposition has a substantial effect on the magnetic values of the $\mathrm{Co}-\mathrm{Cr}$ films. ${ }^{2,7}$ We investigated the properties of $\mathrm{Co}-\mathrm{Cr}$ films on glass and $\mathrm{Si}$ substrates up to temperatures of $350^{\circ} \mathrm{C}$.

For high substrate temperatures during sputtering $\left(T_{\mathrm{sp}}=250^{\circ} \mathrm{C}\right)$, the hysteresis loops of $0.5 \mu \mathrm{m}$ thick $\mathrm{Co}-\mathrm{Cr}$ films on $\mathrm{Si}(111)$ substrates exhibit a high coercivity perpendicular to the film plane $H_{c}$ (perpen) but also a large relative remanence in the plane of the film $m_{r}$ (para) (Figure 17). For $T_{\mathrm{sp}}=100^{\circ} \mathrm{C}, H_{c}$ (perpen) is less than at room temperature (RT), but $m_{r}$ (para) is between the values at $\mathrm{RT}$ and at $250^{\circ} \mathrm{C}$. In the range extending from $20^{\circ} \mathrm{C}$ to $350^{\circ} \mathrm{C}, m_{r}$ (para) increases linearly from 0.07 to 0.24 (Figure 18a). This indicates a markedly poorer magnetic perpendicular orientation at high substrate temperatures. $H_{c}$ (perpen)(Figure $18 \mathrm{~b}$ ) drops from $90 \mathrm{kA} / \mathrm{m}$ at $\mathrm{RT}$ to $70 \mathrm{kA} / \mathrm{m}$ at $100^{\circ} \mathrm{C}$ and rises to a maximum of $160 \mathrm{kA} / \mathrm{m}$ for $T_{\mathrm{sp}}=250^{\circ} \mathrm{C}$. At this substrate temperature $H_{c}$ (para) also reaches its maximum of $75 \mathrm{kA} / \mathrm{m}$. The different orientation of the $\mathrm{Si}$ substrates does not affect the magnetic behavior of the Co-Cr films. The minimum in $H_{c}$ (perpen) at $T_{\mathrm{sp}}=100^{\circ} \mathrm{C}$ could be due to an incipient diffusion of $\mathrm{Co}-\mathrm{Cr}$ into the Si substrate.

The saturation magnetization $M_{s}$ of the Co-Cr films on $\mathrm{Si}$ decreases from $0.5 \mathrm{~T}$ at RT (this corresponds to sputtered Co-Cr films containing 21 at.\% of $\mathrm{Cr}^{8}$ ) to $0.38 \mathrm{~T}$ at $T_{\mathrm{sp}}=300^{\circ} \mathrm{C}$ (Figure 19). This is the $M_{s}$ value for a homogeneous $\mathrm{Co}-\mathrm{Cr}$ alloy containing 21 at. $\%$ of $\mathrm{Cr} .^{9}$ The high $M_{s}$ value at $\mathrm{RT}$ is due to a segregation of $\mathrm{Cr}$ at the crystallite boundaries. ${ }^{8}$ Thus, the decrease in the $M_{s}$ value at high temperatures should be an indication of the increasing homogenization of the $\mathrm{Cr}$ distribution as a result of the higher diffusion rate.

The $m_{r}$ (para) values of $\mathrm{Co}-\mathrm{Cr}$ on glass substrates as a function of substrate temperatures (Figure 20a) show the same trend as those on Si substrates. The only difference being that the rise in $m_{r}$ (para) with rising $T_{\mathrm{sp}}$ is less for $T_{\mathrm{sp}}<100^{\circ} \mathrm{C}$. Thus it appears that the two substrates have the same effect on the magnetic parameters at higher temperatures.

The changes in the coercivity of the Co- $\mathrm{Cr}$ magnetic films on glass substrates (Figure 20b) are also similar to those on Si substrates. The only difference is that the minimum in $H_{c}$ (perpen) at $T_{\mathrm{sp}}=100^{\circ} \mathrm{C}$ was not found.

The relationships between the magnetic properties and the texture of magnetic films will now be discussed. The magnetic measurements indicate a poorer perpendicular magnetic orientation of $\mathrm{Co}-\mathrm{Cr}$ with rising substrate temperature,

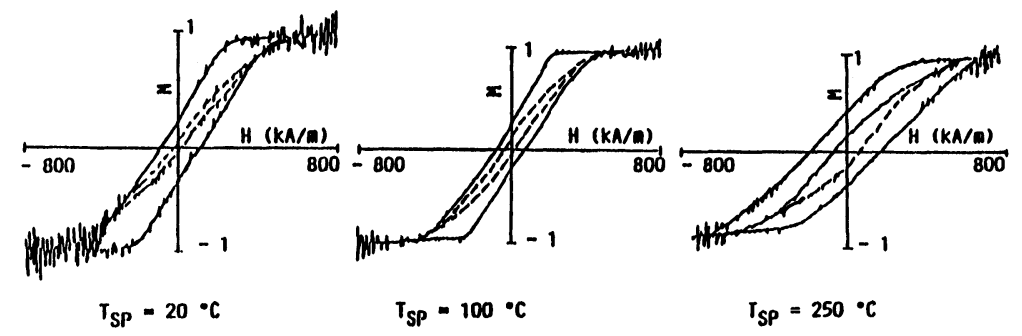

Figure 17 Hysteresis loops (perpendicular (-), and parallel (---)) of $\mathrm{Co}-\mathrm{Cr}$ films on $\mathrm{Si}(111)$ substrates sputtered at different substrate temperatures $T_{\mathrm{sp}}$. 

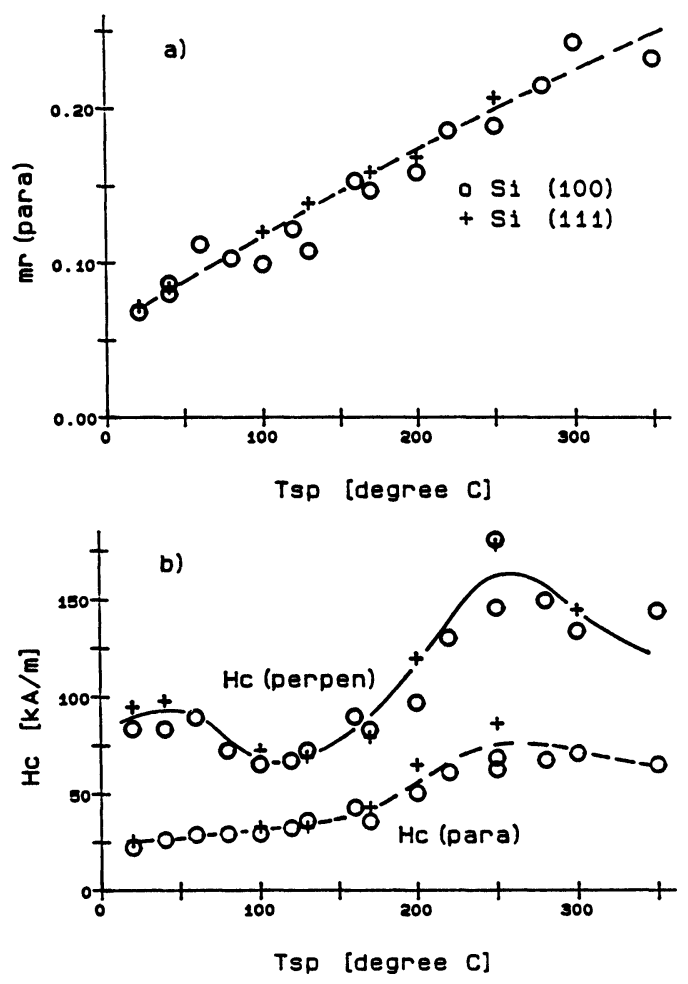

Figure 18 Co-Cr films on Si substrates (a) $m_{r}$ (para) as a function of $T_{\mathrm{sp}}$ (b) $H_{c}$ as a function of $T_{\mathrm{sp}}$.

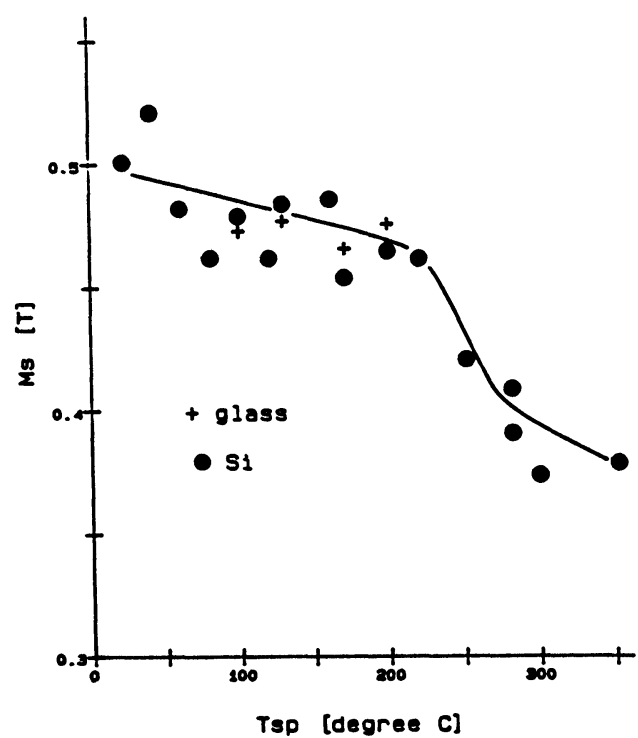

Figure 19 Satuaration magnetization $M_{s}$ of $\mathrm{Co}-\mathrm{Cr}$ films on $\mathrm{Si}$ and glass, sputtered at different temperatures $T_{\text {sp. }}$. 

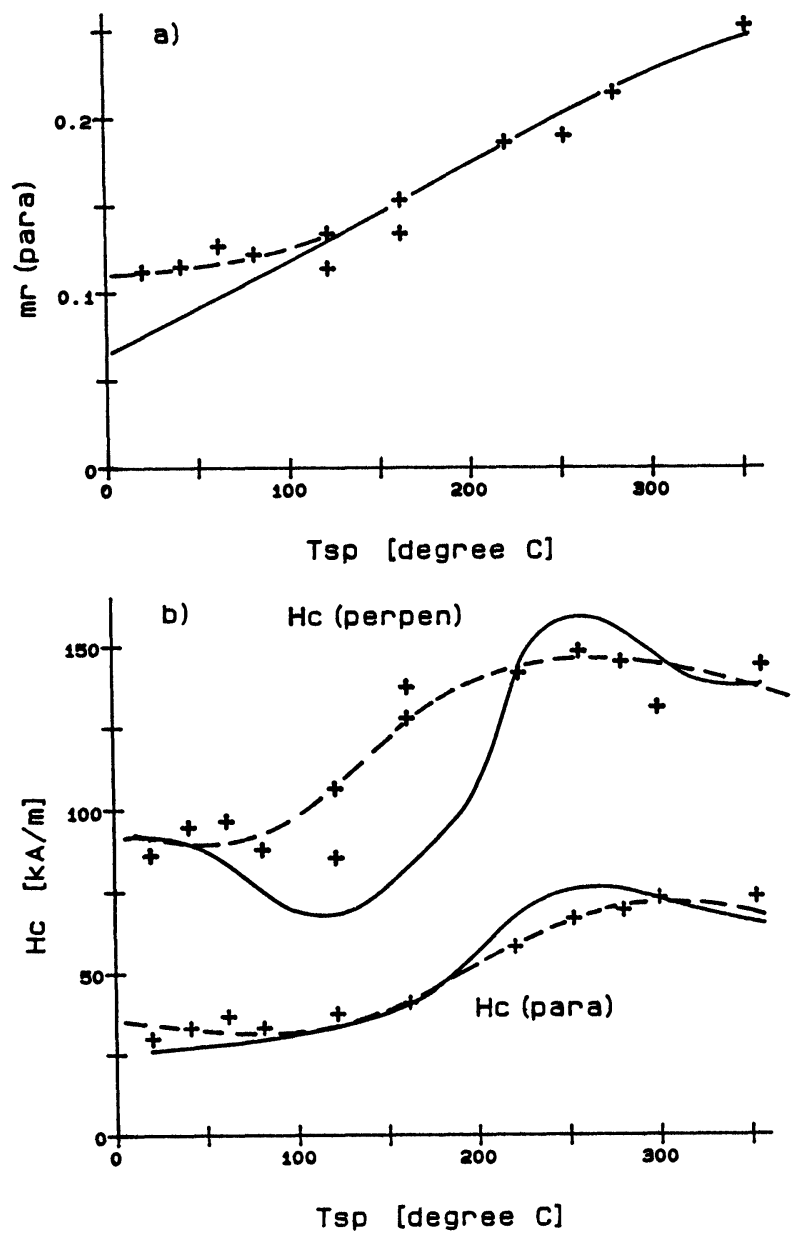

Figure $20 \mathrm{Co}-\mathrm{Cr}$ films on glass (+); (- on $\mathrm{Si})$. (a) $m_{r}$ (para) as a function of $T_{\text {sp. }}$ (b) $H_{c}$ as a function of $T_{\text {sp }}$.

particularly in view of the $m_{r}$ (para) values. Figure 21 shows both the hysteresis loops and also the (002) pole figure of $\mathrm{Co}-\mathrm{Cr}$ on $\mathrm{Si}(111)$ substrates at room temperature and for a substrate temperature of $250^{\circ} \mathrm{C}$ during sputtering. An extremely sharp perpendicular orientation of the $c$ axis is found at room temperature. At $T_{\mathrm{sp}}=250^{\circ} \mathrm{C}$, the orientation distribution of the $c$ axis is very wide and two preferred orientations are found at an $\chi$ angle of $60^{\circ}$. This deviation from the perpendicular orientation of the $c$ axis begins at $T_{\mathrm{sp}}=230^{\circ} \mathrm{C}$. Although the $c$ axis of the crystallites have a preferred perpendicular orientation up to $220^{\circ} \mathrm{C}$, the distribution of this orientation becomes increasingly wider with higher temperatures, as the full width at half maximum (FWHM) of the rocking curves of the $\mathrm{Co}-\mathrm{Cr}$ film show (Figure 22). On Si substrates, this widening from $1^{\circ}$ to $2^{\circ}$ is very small, whereas, in the case of glass substrates, it increases from a value of $3^{\circ}$ at 

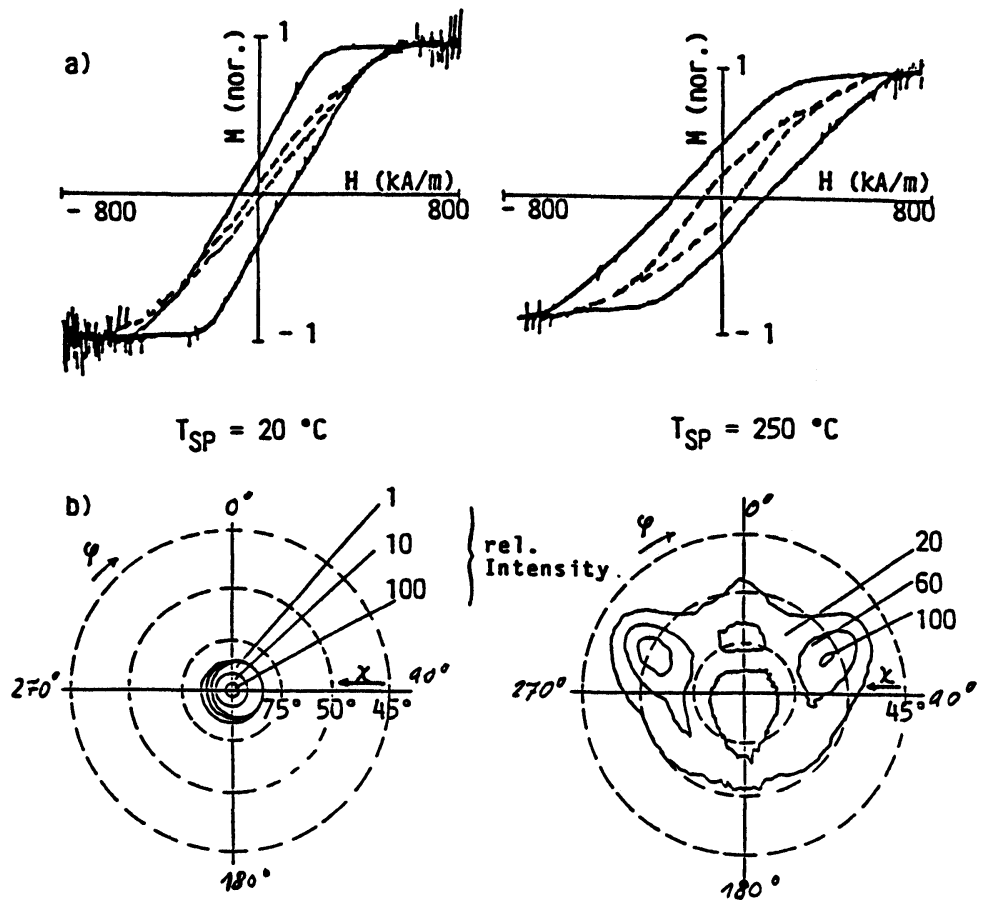

Figure 21 Hysteresis loops. (a) and (002) pole figures. (b) of $\mathrm{Co}-\mathrm{Cr}$ films sputtered on $\mathrm{Si}(111)$ substrates at different temperatures $T_{\mathrm{sp}}$.

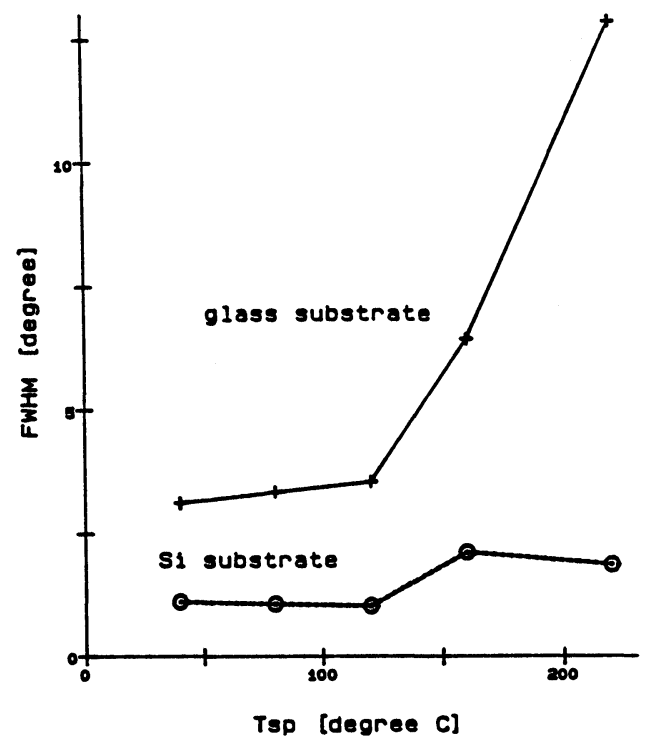

Figure 22 Full width at half maximum (FWHM) of Co-Cr films on $\mathrm{Si}(111)$ and glass substrates as a function of $T_{\mathrm{sp}}$. 
$40^{\circ} \mathrm{C}$ to $12^{\circ}$ at $220^{\circ} \mathrm{C}$. For higher temperatures FWHM values were larger than $20^{\circ}$.

In Figure 23 the maximum intensity $\left(I_{\max }\right)$ of the rocking curves is plotted against the substrate temperature. If we approximate the rocking curve (Figure 9) by a gaussian function:

$$
I(\theta) \sim I_{\max } \times \exp \left(-a \times\left(\theta-\theta_{\max }\right)^{2} / \Delta \theta\right)
$$

we find a good agreement between the measurements and the model curve (Figure 9). By integrating $I(\theta)$ with respect to $d(\theta)$ and assuming a rotational symmetry we obtain:

$$
I_{\max } \sim \Delta \theta^{-2}
$$

Comparison of two measurements yields:

$$
I_{\max 1} / I_{\max 2}=\left(\Delta \theta_{2} / \Delta \theta_{1}\right)^{2}
$$

If the $I_{\max 2}$ values for the other substrate temperatures are calculated from $I_{\max }$ at $T_{\mathrm{sp}}=40^{\circ} \mathrm{C}$ and the measured FWHM (Figure 22), the dashed lines of Figure 23 are obtained. The good agreement with the measurements shows that it is possible to model the rocking curve using a gaussian function.

A correlation of the crystallographic perpendicular orientations of the $c$ axis with the magnetic perpendicular orientations is shown in Figure 24a in which $m_{r}$ (para) was plotted against the full width at half maximum of the rocking curves. Here clear differences are revealed between $\mathrm{Co}-\mathrm{Cr}$ magnetic films on glass and $\mathrm{Si}$ substrates. In the case of glass, increasing $m_{r}$ (para) values correlate with increasing

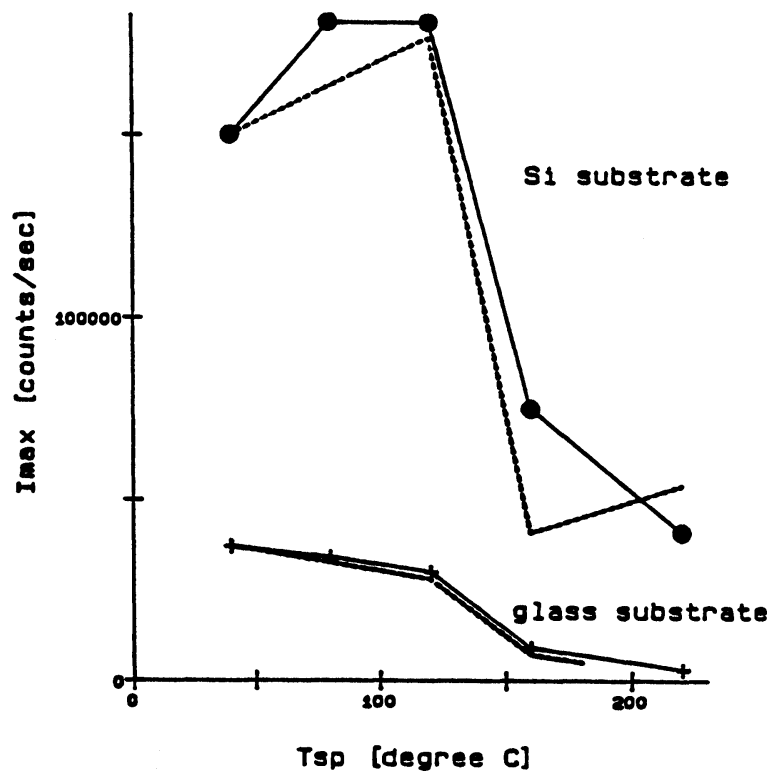

Figure 23 Maximum intensity of rocking curves (see Figure 9) of $\mathrm{Co}-\mathrm{Cr}$ films on $\mathrm{Si}$ and glass as a function of $T_{\text {sp }},(\longrightarrow)$ measured values, (-- ) calculated values. 


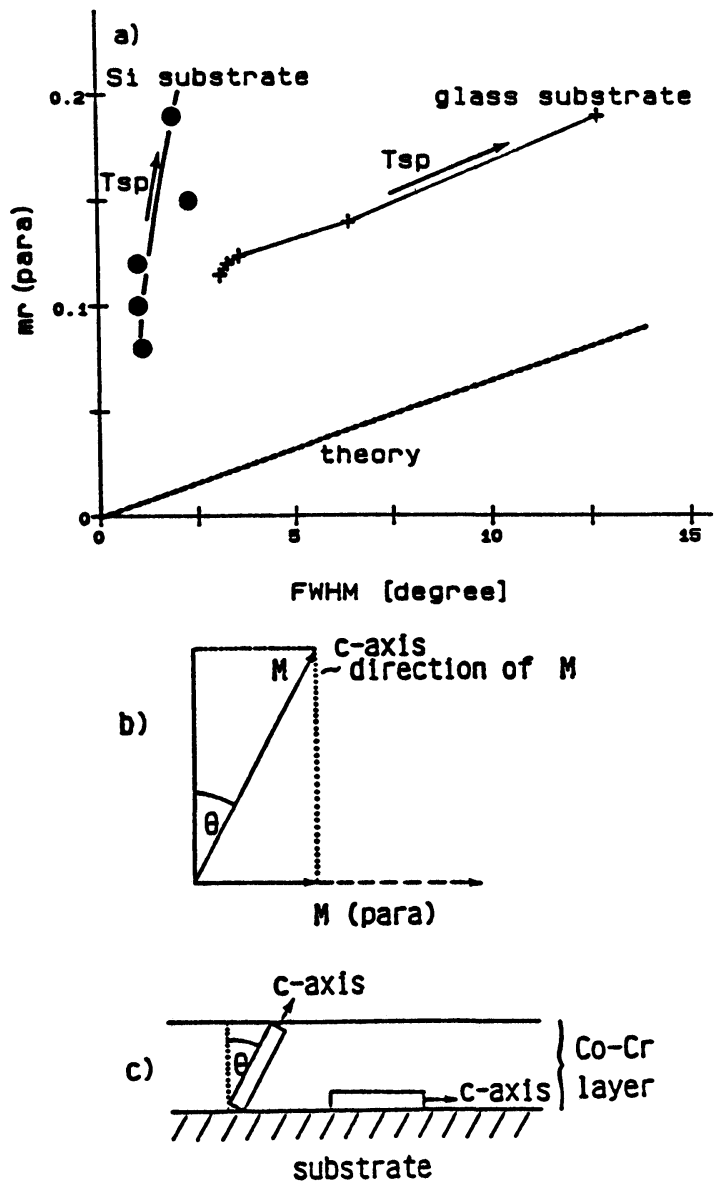

Figure 24 (a) $m_{r}$ (para) of $\mathrm{Co}-\mathrm{Cr}$ films on glass and $\mathrm{Si}$ as a function the full width at half maximum (FWHM) of the rocking curves. (Samples were made at different $T_{\mathrm{sp}}$; $(---)$ represents theoretical values). (b) Connection between $c$ axis distribution (magnetic moment parallel to $c$ axis) and magnetic moment parallel to the film plane (M(para)). (c) The two possibilities of the orientation of $\mathrm{Co}-\mathrm{Cr}$ crystallites at high $T_{\text {sp }}$.

FWHM values. On $\mathrm{Si}, m_{r}$ (para) increases for higher substrate temperatures although FWHM remains almost constant.

Two possible orientations of the Co-Cr crystallites (Figure 24c) are used for the purpose of interpretation:

a) crystallites whose $c$ axis are preferentially perpendicular to the plane of the film,

b) crystallites whose $c$ axis are in the plane of the film.

Crystallites of type a) contribute to the parallel remanent magnetization $M_{r}$ (para) as a result of their projection, i.e. the rocking curve (Eq. 1) has to be weighted 
with $\sin (\theta)$ (Figure 24b). The integration over $\theta(\Delta \theta$ in radian measure) yields:

$$
m_{r}(\text { para })=0.35 \Delta \theta
$$

This relationship is entered in Figure 24a as dotted curve and shows that the increase in $m_{r}$ (para) which is observed in the case of $\mathrm{Co}-\mathrm{Cr}$ on glass is the result of the broader orientation distribution of the $c$ axis at higher substrate temperatures.

Crystallites of type b) contribute fully to $M_{r}$ (para). This probably explains the increase in $m_{r}$ (para) at higher substrate temperatures in the case $\mathrm{Co}-\mathrm{Cr}$ on $\mathrm{Si}$. The number of crystallites with a $c$ axis orientation parallel to the sample surface probably increases with increasing substrate temperature. From the literature ${ }^{2}$ it is known that the boundary layer of the substrate, in particular, is built up of such misoriented $\mathrm{Co}-\mathrm{Cr}$ crystallites. The thickness of this layer probably increases at elevated temperature.

\section{CONCLUSION}

The structure of the magnetic film should be elucidated for the purpose of systematically developing coherent magnetic storage media with high storage density and certain magnetic properties. In particular, the parameters which are important for storage, such as the coercivity or the remanent magnetic flux, may be varied within a wide range by making use of the structure of the magnetic film. By means of examples it has been shown how the morphology and the magnetic properties are altered by sputter etching, by sublayers and by substrate temperature in the case of perpendicularly oriented sputtered $\mathrm{Co}-\mathrm{Cr}$ films on glass and Si substrates. A main part plays the orientations of the crystallites which is particularly well characterized by means of X-ray texture investigations.

\section{ACKNOWLEDGMENT}

This work was supported by the european community in the ESPRIT program 957.

\section{References}

1. Heilmann, P., Kuhlmann, U. and Haberkorn, H. (1985). J. Phys., C6, 97-100.

2. Wielinga, T. (1983). Thesis, Twente University.

3. Glocker, R. (1949). Materialprüfung mit Röntgenstrahlen, Springer Verlag.

4. Wyckoff, R. W. G. (1963). 1, Interscience Pub., New York.

5. Fumatomo, M., Honda, Y., Kakibuyashi, H. and Yoshida, K. (1985). IEEE Trans. Magn., 21, 1426-1428.

6. Yamaguchi, H. and Yanagisawa, M. (1986). IEEE Trans. Magn., 22, 576-578.

7. Hoffmann, H., Kochanowsky, L., Mändl, H., Kastner, K., Mayr, M., Münz, W. and Röll, K. (1985). IEEE Trans. Magn., 21, 1432-1434.

8. Nesaka, Y., Hishiyama, S. and Fujiwara, H. (1982). Proc. of Sendai Symp. on Perpendicular Magnetic Recording.

9. Sugita, R., Matsushita Electric Industrial Co., EP 36,717 (US 4,429,019), (04.03.1981). 